\title{
A integralidade da atenção à saúde como eixo da organização tecnológica nos serviços
}

\author{
Comprehensive health care \\ as the core concept for technological organization in services
}

\author{
Diego Bonfada ${ }^{1}$ \\ José Rodolfo Lopes de Paiva Cavalcante ${ }^{1}$ \\ Dayane Pessoa de Araujo ${ }^{1}$ \\ Jacileide Guimarães ${ }^{2}$
}

${ }^{1}$ Universidade do Estado do Rio Grande do Norte. Rua André Sales 667, Paulo VI. 59300-000 Caicó RN. diegobonfada@hotmail.com ${ }^{2}$ Universidade Federal do Rio Grande do Norte
Abstract Despite the marked achievements of the Unified Health System (SUS), implementation of its principles and guidelines has not yet been fully achieved. Therefore, this article reflects on comprehensiveness and technology reorganization based on soft technologies and expanded clinical care, not only as guidelines, but as core elements for a new way of thinking about health. It involves a literature review that not only seeks an overview of ideas about the subject, but also attempts to establish a dialogue between the authors in reference to reflect on daily services, especially in hospital. We found that most of the obstacles to improvement of the services of the SUS are related to the predominance of curative medical care in the thinking process of health professionals. Breaking with that logic, comprehensive care, technological reorganization and expanded clinical care can foster closer approximation between professionals and users, at the same time as actions come to be dictated by the individuals and the community, breaking with the vertical imposition of conduct. Thus, the traditional 'biologicist' approach to clinical care needs to be deconstructed to break with the logic of manifest suffering and "treat 'em and street 'em" philosophy.

Key words Human resources in health, Health policy, Health services
Resumo Apesar das conquistas alcançadas pelo Sistema Único de Saúde (SUS), a implantação dos seus princípios e diretrizes ainda não aconteceu de forma plena. Diante disso, refletiremos ao longo deste artigo sobre a integralidade e a reorganização tecnológica a partir das tecnologias leves e da clínica ampliada, não só como diretrizes, mas como elementos norteadores de uma nova forma de pensar/fazer saúde. Trata-se de uma revisão de literatura que não se ocupa somente em trazer um apanhado de ideias sobre o tema, mas que buscou estabelecer um diálogo entre os autores referenciados para refletir sobre o cotidiano dos serviços, em especial o hospitalar. Constatamos que a maior parte dos entraves para a melhoria dos serviços prestados no espaço do SUS diz respeito ao predomínio do modelo médico assistencial curativista no fazer/pensar saúde dos profissionais. Rompendo com essa lógica, a integralidade da atenção, a reorganização tecnológica e a clínica ampliada defendem uma maior aproximação entre profissionais e usuários, na medida em que, as ações passem a ser orientadas pelas necessidades dos indivíduos e coletividade, rompendo com a imposição vertical das condutas. Sendo assim, a clínica tradicional biologicista precisa ser desconstruída e deve-se romper com a lógica do sofrimento manifesto e da queixa-conduta. Palavras-chave Recursos humanos em saúde, Politica de saúde, Serviços de Saúde 


\section{Introdução}

O movimento brasileiro da Reforma Sanitária tornou possível a concretização de um serviço de saúde regido pelos princípios da universalidade, equidade e integralidade, cujas ações estejam voltadas para a resolução das necessidades sociais e, por consequência, para os determinantes do processo saúde-doença da população. Nessa perspectiva, surgiu o SUS, que foi oficializado na Constituição Federal de 1988.

No entanto, para a efetivação dos princípios e diretrizes anteriormente citados, torna-se indispensável repensar o direcionamento da produção dos serviços em saúde que historicamente vem sendo desempenhada sob a orientação hegemônica do modelo médico-assistencial privatista, voltado para a cura do corpo individual, em suas manifestações patológicas, o que a caracteriza fragmentadora, curativista e pontual. Nesse sentido, o grande desafio a ser enfrentado pelo setor saúde consiste em romper com a lógica do sofrimento manifesto, da queixa-conduta e da fragmentação das intervenções terapêuticas, passando a trabalhar sob uma ótica integral, isto é, (re)pensando as práticas em saúde a partir da leitura ampliada da realidade de vida dos indivíduos, garantindo que as intervenções se dêem em consonância com as singularidades de cada um deles.

Outro desafio a ser assumido pelos profissionais de saúde é a valorização das relações interpessoais em suas práticas cotidianas. Isso se torna indispensável à medida que suas prerrogativas apontam para um maior vínculo e o fortalecimento das relações entre os profissionais de saúde e das interações destes com os usuários dos serviços, o que, inevitavelmente, acarretará em significativas transformações no pensar/fazer saúde ${ }^{1}$.

Sob este olhar, passaremos a refletir no decorrer deste texto sobre instrumentos apontados como importantes para a consolidação de serviços de saúde articulados com as necessidades sociais no Brasil: a integralidade da assistência, a reorganização tecnológica a partir das tecnologias leves e da clínica ampliada. Será focada em um momento de nossa análise a realidade hospitalar por a entendermos como espaço de manifestação máxima do modelo hegemônico ideológico da produção dos serviços de saúde pautado exclusivamente no saber médico da clínica tradicional.

\section{Construção Polissêmica da Integralidade}

Refletindo sobre a realidade da produção dos serviços de saúde no Brasil, percebemos que a integralidade, além de ser uma diretriz do SUS, é uma bandeira de luta, um enunciado de certas características do sistema de saúde, de suas instituições e de suas práticas que são consideradas desejáveis por alguns. Ela tenta falar de um conjunto de valores pelos quais vale lutar, pois se relacionam a um ideal de uma sociedade mais justa e solidária ${ }^{2}$.

Nesse sentido, Mattos 2 esclarece que "toda imagem objetivo tenta indicar a direção que queremos imprimir à transformação da realidade". Dessa forma, a integralidade acaba adquirindo diversas concepções mediante o contexto e as pessoas que a pensaram. Assim, assume um caráter polissêmico materializado nas seguintes concepções: integralidade relacionada à maneira como os serviços se organizam e integralidade enquanto expressão do movimento da medicina integral, que serão debatidos em seguida.

Ao discutirmos a integralidade relativa à maneira como se organizam as práticas de saúde, iniciamos questionando: de que forma, então, o Estado quer chegar a estabelecer uma assistência integral se a base da produção dos serviços de saúde hoje corresponde a programas verticalizados que não respondem às necessidades e a realidade local? Essa questão problema se torna um elemento chave, uma vez que, na perspectiva da integralidade, os serviços devem dar conta das necessidades ampliadas de saúde da população. Nessa perspectiva, as intervenções em saúde requerem que o espaço singular de vivência dos indivíduos seja respeitado, aspecto este que uma assistência planificada de "cima para baixo" (grifos nossos) não nos permite perceber.

Outra reflexão pertinente é que o caráter imprevisível dos elementos do processo saúde-doença, determinantes da cura e da morte dos indivíduos, é marcado pelo alto grau de subjetividade das relações entre profissionais e usuários e daqueles com os serviços. Essa subjetividade e imprevisibilidade não devem ser negadas sob o risco de estarmos excluindo elementos socioculturais essenciais para a compreensão das dificuldades enfrentadas pelas instituições de saúde ${ }^{3}$.

Analisando agora o outro sentido assumido pela integralidade em nossa argumentação, e que recebe maior destaque neste artigo, apontamos que ele tem seus referenciais epistemológicos desenvolvidos em um movimento de revolução na saúde chamado de Medicina Integral. 
A medicina integral critica fortemente a fragmentação das ações perante os usuários dos serviços de saúde. Tal prática está inserida em um contexto fortalecedor das especialidades médicas, onde os profissionais de saúde recortam os pacientes, atentando durante a operacionalização de suas práticas somente para os aspectos ligados ao funcionamento dos aparelhos ou sistemas focos da sua especialização ${ }^{2}$.

Esse sentido traz à tona uma das críticas mais frequentes ao arranjo das práticas em saúde que é a ênfase na assistência individual, curativista e biologicista, que impossibilitam visualizar o indivíduo em sua inserção no espaço coletivo. Como consequência, temos uma atenção à saúde limitada aos trâmites da queixa-conduta, que em pouco contribui para a transformação da realidade de saúde/doença individual e coletiva.

A esta forma de abordagem do indivíduo é denominada de Clínica Oficial (clínica clínica). Porém, esse modelo de atenção é insustentável devido aos seus altos custos para o financiamento das ações e à reduzida capacidade operacional do profissional. Além disso, estabelece uma cadeia de dependência quase impossível de ser integrada em projetos terapêuticos coerentes ${ }^{4}$.

\section{A clínica curativista como obstáculo à integralidade nos serviços de saúde hospitalares}

Mesmo diante de tantas limitações, historicamente, a assistência individual e curativista assumiu o papel de protagonista da produção dos serviços de saúde. Tal situação ganha força na atualidade pela existência de uma série de determinantes. Um deles seria a formação profissional ainda embasada em referências que não dão suporte para a realização da assistência que tenha como eixo estruturante a integralidade da atenção à saúde e que, sobretudo, esteja voltada para a transformação da realidade de saúde dos mais diversos espaços sociais. Outro determinante é a influência mercadológica capitalista que, sob a influência das grandes empresas em saúde, principais privilegiadas por essa organização, aponta a atenção curativa como sendo rentável e a saúde como uma mercadoria a ser consumida e negociada.

Não queremos aqui negar a importância da clínica, muito pelo contrário, ela é um instrumento valoroso e imprescindível em eventos inevitáveis como a ocorrência de patologias ou de acidentes em algum momento da vida de uma pessoa, por dispor de terapêuticas e ações vitais em tais momentos. O que pretendemos na verdade é discutir limites e possibilidades desse modelo pensado como único e desarticulado, tendo sempre em vista as novas necessidades de intervenção pautadas na integralidade. Dito de outra forma, reconhecer a insuficiência desse modelo que pode ser superada na medida em que a tecnologia do modelo clínico é (re)situada no trabalho em saúde.

Porém, em vez de repensar sua forma de pensar/fazer saúde, o saber clínico dominante tem apontado para a construção de conhecimentos que fazem parte de uma manobra para fazer crer que $o$ atendimento das necessidades individuais, em sua soma, equivale ao atendimento das necessidades coletivas ${ }^{5}$.

Isso intensifica uma realidade onde os serviços de saúde não dão conta da integralidade e, consequentemente, as necessidades e demandas trazidas pela população, criada em suas manifestações subjetivas e inerentes a suas realidades, são relegadas em nome de um modelo hegemônico voltado para o fortalecimento da iniciativa privada e do lucro.

Assim, a clínica precisa ser repensada. As condutas terapêuticas podem e devem constituir-se enquanto mote na assistência. Mas, o desafio está em não torná-las homogêneas e caminhar na perspectiva da construção de projetos terapêuticos individuais que considerem a experiência individual de sofrimento dos sujeitos, haja vista que os mesmos estão expostos a potenciais de riscos e benefícios singulares, característicos dos seus "modos de andar a vida".

Mas, isso não deveria ser papel de Unidade Básica de Saúde (UBS)? "Hospital é lugar de cura!" Vêm-nos os gritos da ideologia dominante sob essas perguntas. Porém, a clínica não pode ser pensada na perspectiva de que a prevenção se dá nas UBS e a cura nos hospitais, tendo em vista a proposta constitucional do SUS.

Em tal proposta, o espaço hospitalar compreende o atendimento de média e alta complexidade que impõem a necessidade de reabilitação do usuário. Talvez essa lógica aponte realmente o que seria o papel básico do hospital, mas não o essencial diante dos desafios que aqui estão sendo levantados. O real papel do hospital, sob a ótica do SUS, está em assumir o desafio de estabelecer espaços de (re)discussão das práticas visando a (re)orientação do pensar/fazer saúde, de modo especial a dicotomia cura/prevenção. Desafio este em estreita relação com a operacionalização da integralidade na realidade dos serviços de saúde. 
Finalmente, como argumento definitivo contra a ideia de conformação do espaço da atenção básica como preventivo e o hospital essencialmente curativo, apontamos que a integralidade do cuidado, como possibilidade de respeito às reais necessidades de um sujeito social, frequentemente ultrapassa os limites hierárquicos do sistema de saúde brasileiro. Não há integralidade se essa assertiva não se tornar verdadeira. Nesse sentido, a integralidade pode ser atingida em rede e quando uma equipe, em um serviço em particular, articula suas práticas e consegue escutar e atender as necessidades de saúde trazidas pela população individual e coletivamente ${ }^{6}$.

Nesse sentido, é preciso romper com a lógica do hospital como espaço exclusivo de e para cura e reconhecê-lo enquanto copartícipe e corresponsável pelo processo de mudança das condições de vida da população. Assim, dois instrumentos mostram-se como imprescindíveis para assegurar a recomposição das práticas neste espaço: o mecanismo de referência e contrarreferência e a articulação intersetorial como importantes para uma prática integral na rede assistencial, já que, conforme discutido no parágrafo anterior, a integralidade se faz dentro de uma instituição, mas também ultrapassar as paredes da instituição, visto a complexidade das demandas trazidas pela população. Complexidade está gerada em todas as contradições e conflitos da sua gênese sóciohistórica.

Portanto, pensar a integralidade no espaço hospitalar requer a (re)significação da prática assumida historicamente pela instituição. Prática esta, essencialmente atrelada à utilização de equipamentos e aparelhagem sofisticada como garantia exclusiva de uma assistência de qualidade.

\section{A organização tecnológica e a clínica ampliada enquanto meios/instrumentos indispensáveis à contemplação da integralidade}

Contribuindo com a tentativa de mudança na dinâmica da organização tecnológica no espaço do hospital, na perspectiva de romper com essa lógica que limita a atuação desta instituição, uma vez que é espaço privilegiado de conformação da clínica, passaremos agora a uma reflexão sobre a dinâmica dos serviços de atuação hospitalar de modo geral.

Não estamos propondo a construção de uma receita de integralidade via reorganização tecnológica para uma realidade hospitalar hipotética. Isso seria uma contradição com a nossa crítica inicial à imposição de medidas verticalizadas e sem o respeito às singularidades. $\mathrm{O}$ que queremos é construir conhecimento nessa perspectiva, refletindo sobre pontos críticos, evidenciando espaços de potencialidades e ressaltando necessidade de mudanças sobre questões bem particulares da dinâmica do serviço hospitalar, traçando, nesse caminhar, algumas diretrizes e encaminhamentos que não tem pretensões de se tornarem verdades universalmente aplicadas.

O ponto de partida para nossa discussão é a organização de equipes especialmente capacitadas para o acolhimento nos serviços de urgência. Tais equipes teriam a função de reconhecer e encaminhar os usuários que necessitam de cuidados para encontrarem a assistência mais apropriada em outros serviços da rede municipal/regional de saúde, sendo o próprio hospital responsável pela referência ${ }^{6}$.

Não é simplesmente falar para o paciente que procure outro serviço de forma fria, impessoal e sem qualquer demonstração de empatia. Tratase de perceber-se como responsável pelo "transitar" do paciente na rede, adotando a postura de quem conhece profundamente a realidade regional e orienta o usufruto dos serviços disponíveis da melhor maneira possível para o cidadão. Nesse sentido, as carências e restrições assistenciais não devem ser vistas como um problema particular do paciente, mas sim como o surgimento de uma demanda que precisa ser resolvida por todos os atores envolvidos.

Nesse sentido, recompor as práticas no espaço do hospital, na perspectiva de ampliar a clínica a partir da integralidade e da reorganização tecnológica, significa observar além do que os aspectos palpáveis e aferíveis, como os sinais e os sintomas, por exemplo. Significa, acima de tudo, agir sabendo que o trabalho não cessa ali, com a cura, e sim, há uma continuidade.

Nessa perspectiva, a alta hospitalar deve ser pensada como um momento privilegiado para a garantia da continuidade da assistência em outras instâncias da rede de saúde, não apenas de forma burocrática, cumprindo um papel de "contrarreferência" estabelecido pelo SUS, mas pelo compromisso de sujeito institucional na manutenção da continuidade de cuidado necessária àquele paciente específico. Mesmo o período de internação, que antecede a alta, pode ser aproveitado para a efetivação de ações que fortaleçam a autonomia do usuário, visando a reconstrução de seu modo de levar a vida ${ }^{6}$.

Percebemos, com esta discussão, que ampliar a assistência significa também ser capaz de perce- 
ber que por trás de uma manifestação individual de sofrimento há todo um contexto de vida que determina o surgimento desta ou daquela patologia, como também pode, em condições futuras, resultar em outros sofrimentos-manifestos que não aqueles do momento. Além disso, devemos também levar em consideração que esse contexto de vida, ao qual fizemos referência há pouco, se estabelece dentro de um espaço coletivo. Portanto, compreender o indivíduo requer antes de tudo reportá-lo ao lócus de sua inserção social, sem que haja, no entanto, a massificação do todo e sem negar as particularidades que lhes são inerentes. Corroborando com essa discussão, Queiroz e Salum ${ }^{7}$ afirmam que: "para situar enfim o indivíduo, enquanto unidade singular, essa totalidade tem ainda que ser compreendida na unidade dialética coletivo $\mathrm{x}$ indivíduo, pois como tal, são interdependentes".

Nesta perspectiva, uma assistência procedimento-centrada, isto é, uma assistência cuja finalidade visa dar resposta às manifestações morfofisiológicas através da utilização de técnicas tidas como próprias à ocasião, não seria capaz de garantir esse suporte.

Nesse sentido, o desenvolvimento de protocolos ou de rotinas, práticas bastante presentes nos hospitais, não garantem a integralidade da assistência. Pois, segundo Mattos ${ }^{8}$, a criação destes protocolos não é articulada às demandas trazidas pelos usuários dos serviços. Sendo assim, o autor aponta a necessidade de compreender o contexto de cada pessoa, adotando uma postura que identifique as necessidades de prevenção e as assistenciais, e que seleciona as intervenções a serem ofertadas.

Esta forma de intervenção é denominada de clínica ampliada ou clínica do sujeito, em virtude da importância que este representa para a intervenção em saúde, que tem como eixo norteador a integralidade da atenção, uma vez que partimos do pressuposto de que cada pessoa interfere de modo ativo em seu processo saúde/doença, sem perder de vista a determinação social desse fenômeno".

Falar sobre clínica ampliada requer, antes de tudo, (re)pensar a organização tecnológica do trabalho. Neste sentido, acreditamos que a clínica ampliada seja o espaço de materialização da integralidade, tendo como via o uso de tecnologias leves, à medida que estas darão o suporte necessário ao estabelecimento do acolhimento/ vínculo, aspectos estes que os serviços de saúde hoje carecem, não só no hospital, mas em todos os níveis de atenção.
Ratificando, o vínculo citado no parágrafo anterior sustenta-se em um território próprio das tecnologias leves, uma vez que, se processa em momentos de relação entre trabalhadores e usuários que objetivam a escuta e a responsabilização, articulados com a construção de projetos de intervenção que sejam compromissados com as necessidades de saúde dos usuários".

Portanto, a organização tecnológica do trabalho, orientada pelo princípio da integralidade, requer uma relação democrática entre quem produz e quem consome o serviço na perspectiva do atendimento às necessidades sociais. Porém, essa perspectiva apela para um trabalho de natureza interdisciplinar, portanto, coletivo e com trabalhadores coletivos "que desenvolvem processos cooperativos que não são meramente a soma dos processos de trabalho e habilidades dos conjuntos dos membros da equipe multiprofissional"7.

Nesse sentido, assumir a constituição do trabalho coletivo e do trabalhador coletivo significa construir relações mais democráticas no espaço do trabalho em saúde. Implica, portanto, compreender o trabalho coletivo como resultado "do volume total do trabalho global necessário à transformação do objeto [...] e não simplesmente da somatória dos trabalhos parciais em saúde" . Não significa, portanto, dizer que o trabalho parcial seja anulado, mas que se subordina ao trabalhador coletivo

\section{Considerações Finais}

Considerando as reflexões realizadas até o momento, lançar mão das tecnologias leves, enquanto ferramentas para a efetivação de uma atenção integral à saúde, passa a ser o grande desafio. Com essa compreensão, a clínica ampliada ou a clínica do sujeito torna-se um espaço privilegiado para a conformação da integralidade, uma vez que possibilita a superação das condutas terapêuticas em caráter individual e curativo, o que de fato contribui para uma nova organização tecnológica do trabalho no espaço da produção de serviços de saúde.

Porém, não podemos esquecer que a conjuntura macroestrutural vigente exerce forte determinação na dinâmica particular dos serviços de saúde hoje. Entretanto, que isto não seja visto como uma válvula de escape para os problemas e/ou justificativa para a não tomada de decisões e a não efetivação das transformações. Muito pode ser feito no espaço singular, basta uma mudança na maneira de pensar e agir, pois, o 
microespaço pode sim ser um ambiente de contra-hegemonia. Contudo, ressaltamos que efetivar a integralidade em todo o sistema de saúde extrapola o desejo individual. Desta feita, a organização tecnológica que tem como eixo norteador a integralidade da atenção é uma decisão política que deve ser institucionalizada e incorporada pelos profissionais de saúde.

\section{Colaboradores}

D Bonfada, JRLP Cavalcanti e DP Araújo trabalharam na concepção, no delineamento e na redação do artigo. J Guimarães trabalhou na revisão crítica e na aprovação da versão a ser publicada.
Nesse momento, salta aos olhos de todos nós a necessidade indelével de produzir conhecimentos voltados para a consolidação da integralidade no espaço da atenção, através do fortalecimento de vínculos propiciado pelas tecnologias leves. Esses conhecimentos devem adentrar ao máximo no espaço da formação em saúde, libertando definitivamente as academias das amarras de um velho (1910), mas vivo, relatório Flexner.

\section{Referências}

1. Merhy EE. Engravidando palavras: o caso da integralidade. [cerca de 14p]. [acessado 2009 jun 08]. [Documento da Internet]. Disponível em: acd.ufrj. $\mathrm{br} / \mathrm{nutes} /$ Home\%20LTC/mestrado/arquivos/ semmerhy.pdf

2. Mattos RA. Os sentidos da integralidade: algumas reflexões acerca de valores que merecem ser definidos. In: Pinheiro R, Mattos RA. Construção da integralidade: cotidiano, saberes e práticas em saúde. Rio de Janeiro: Abrasco; 2003.

3. Pinheiro R, Luz M. Práticas eficazes $x$ modelos ideais: ação e pensamento na construção da integralidade. In: Pinheiro R, Mattos RA. Construção da integralidade: cotidiano, saberes e práticas em saúde. Rio de Janeiro: Abrasco; 2003.

4. Nascimento MAA. O desafio da clínica na Saúde da Família. Jornal da Associação Brasileira de Enfermagem 2004; (out, nov, dez):16-18.

5. Mendes Gonçalves RB. Tecnologias e organização social das práticas em saúde: características tecnológicas do processo de trabalho na rede estadual de centros de saúde de São Paulo. São Paulo: Hucitec, Abrasco; 1994.

6. Merhy EE, Cecílio LCO. A integralidade do cuidado como eixo da gestão hospitalar. Campinas (SP): mar, 2003. [acessado 2009 jun 08]. [cerca de 16p.]. [Documento da Internet]. Disponível em: www.hc. ufmg.br/gids/Integralidade.doc

7. Queiroz VM, Salum MJL. Reconstruindo a intervenção de enfermagem em saúde coletiva face à vigilância à saúde. In: $48^{\circ}$ Congresso Brasileiro de Enfermagem; 1996; São Paulo.

8. Mattos RA. A integralidade na prática (ou sobre a prática da integralidade). Cad Saude Publica 2004; 20(5):1411-1416.

9. Campos GWS. Saúde e Paideia. São Paulo: Hucitec; 2003.

Apresentado em 30/06/2009

Aprovado em 06/03/2010

Versão final apresentada em 25/03/2010 